\title{
Preface to the First Issue of Indian Pacific Journal of Accounting and Finance
}

It is a great pleasure and at the same time a challenge to introduce a new journal into the global community, especially when the objective is to publish high quality impactful manuscripts or papers. Although, accounting and finance studies constituted a primary focus for most of the scholars because of our understanding of their values. However, only a few of us spend much time to explore emerging areas. Notwithstanding the challenges, this journal seeks to provide readers throughout the world with technology backed quality peer reviewed scholarly articles on a broad range of established and emergent areas to accounting and finance in particular, and business, economics and social sciences in general. A one on one discussions with distinguished scholars attests to the fact that there is a dire necessity for such a journal in the Indian-Pacific axis.

In order to create a niche for IPJAF as the most authoritative journal on accounting and finance, a team of highly valuable or distinguished scholars has agreed to serve on the editorial board. I am privileged and opportune to have Associate Editor-in-Chief, Aidi Ahmi (Universiti Utara Malaysia), and Associate Editors: Muhammad Ali Abdul Hamid (University of Sharjah, UAE), Bamidele Adepoju (Bayero University), Abayomi Ambali Alaka (Institute of Chartered Accountants of Nigeria), and Dorcas Adebola Babatunde (Afe Babalola University of Ado-Ekiti). Our editorial board members are scholars from several countries worldwide that are actively engaged in academic and professional committees, supervising doctoral thesis and doctoral teaching level courses. The Editorial Board is supported by a group of competent and experienced international review panel members from different continents of the world. With this synergy, the journal brings a significant representation of the field of accounting and finance both in established and developing areas.

Our existence is anchored on the service and dedication of IPJAF editorial board and the editorial team. This inaugural volume consists of five manuscripts. Shitu and Popoola's article, An investigation of Socially Sustainable Behaviour of Local Players in the Supply Chain of Shea Butter: A Role Theory Perspective, explores the roles, practices, and behaviour of local supply chain stakeholders (women entrepreneurs) in Shea nut picking and Shea butter processing in Rural Borgu, Nigeria. Also, the research examines the local buying agents (LBA) who serve as the middlemen between the rural women and the exporters of Shea butter. The findings indicate that the present active engagement and practices of these local stakeholders do not align with the principles of the sustainable supply chain. The paper exposes factors such as gender disparity, weak access to financial support, and information asymmetry as major contributors to the present roles, practices, and behaviour of the local actors.

Lina and Jingga's article, Factors influencing Tax Avoidance activity: An empirical study from Indonesia Stock Exchange, examines the influence of the firm characteristics to tax avoidance activity in the listed companies in Indonesia. The paper adopts the proxies of firm size, leverage, capital intensity, inventory intensity as the business 
characteristics and return on asset and market-to-book ratio as control variables. The result of this research reveals that leverage has a positive influence towards tax avoidance activity, while the rest variables have no influence towards tax avoidance activity.

Adedeji, Popoola and Ong's article, National Culture and Sustainability Disclosure Practices: A Literature Review, investigates the extent to which national culture is an explanatory variable for firm's disclosure choices for sustainable development in the advanced, emerging and developing nations of the world, especially that entities interact in globally knowledge-based economies. The paper identifies that not much work had been done in the area of traits and characteristics in specific national cultural environments and their effects on sustainability disclosures, in particular, social and environmental disclosures. The paper concludes with the recognition of the need to gear up researchers and policy making bodies to encourage the advancement of studies on the intellectual capital concept and resource-based value theory to enhance sustainability development globally.

Imelda and Alodia's article, The analysis of Altman Model and Ohlson Model in Predicting Financial Distress of Manufacturing companies in the Indonesia Stock Exchange, examines the accuracy of the Altman Model and the Ohlson Model in Bankruptcy Prediction. The results of the paper show that the Ohlson Model and the Logit Analysis are more accurate than the Altman Model and the Multiple Discriminant Analysis in predicting bankruptcy of manufacturing firms in the Indonesian Stock Exchange (BEI) in 2010-2014. The paper reveals benchmark for consideration in determining the financial distress of a company such as the ratio of retained earnings to total assets, earnings before interest and taxes to total assets, market value of equity to total liabilities, sales to total assets, debt ratio, and return on assets, working capital to total assets and net income.

Arowolo and Che-Ahmad's article, Quality-differentiated Auditors, Block-holders and Monitoring Mechanisms, seeks to investigate how monitoring mechanisms influence the block-holders in 111 Nigerian non-financial listed companies to resolve the problem of business failures as a result of information asymmetry existing in the relationship of the managements with the shareholders. The study also investigates the mediating effect of the quality-differentiated auditors on the relationship between block-holders and monitoring mechanisms. The findings indicate that the block-holders significantly influence monitoring mechanisms. Also, the results reveal that quality-differentiated auditors positively affect monitoring mechanisms and that it significantly explains the relationship between block-holders and monitoring mechanisms.

It is my conviction that in the coming year, the vision of IPJAF to publish high quality manuscripts in the established and emergent areas of accounting and finance from academic and professional researchers will be attained, maintained and appreciated. As you read throughout this inaugural volume of IPJAF, I would like to remind you that the success of our journal depends on your active participation and those of your colleagues and friends through submission of high quality articles for review and publication. I assure our prospective authors, regardless of the acceptance of your manuscripts or not, to enjoy the benefits IPJAF provides about mentoring nature of our review process, which provides high quality, helpful reviews tailored to assist authors in improving their manuscripts. I acknowledge your support as we strive to make IPJAF the most authoritative journal on accounting and finance for the community of academic, professional, industry, society and government.

\section{Oluwatoyin Muse Johnson Popoola}

Editor-in-Chief 